\title{
QUESTÃO ÉTICO-MORAL NA FORMAÇÃO DOS ENFERMEIROS E MÉDICOS: EFEITOS DE SENTIDOS NOS DISCURSOS DOCENTES ${ }^{1}$
}

\author{
Rita Catalina Aquino Caregnato², Rosa Maria Filipozzi Martini³, Regina Maria Varini Mutti ${ }^{4}$
}

\footnotetext{
${ }^{1}$ Artigo resultante da tese - A questão ético-moral na formação dos enfermeiros e médicos: efeitos de sentidos nos discursos docentes, Programa de Pós-Graduação em Educação da Universidade Federal do Rio Grande do Sul (UFRGS), 2008.

${ }^{2}$ Doutora em Educação. Professor Adjunto da Universidade Luterana do Brasil (ULBRA/Canoas). Professora do Centro Universitário do Vale do Taquari. Rio Grande do Sul, Brasil. E-mail: carezuca@terra.com.br

${ }^{3}$ Doutora em Educação. Professor Adjunto da Universidade de Santa Cruz do Sul. Orientadora da tese. Rio Grande do Sul, Brasil. E-mail: rosamfm@terra.com.br

${ }^{4}$ Doutora em Linguística e Letras. Professor Associado da UFRGS. Co-orientadora da tese. Rio Grande do Sul, Brasil. E-mail: reginamutti@terra.com.br
}

RESUMO: Esta pesquisa teve como objetivo compreender os efeitos de sentidos produzidos no discurso dos sujeitos docentes de enfermagem e medicina sobre a questão ético-moral na formação dos discentes. Pesquisa qualitativa fundamentada pela teoria da Análise de Discurso, da linha francesa de Pêcheux, em interlocução com a teoria de Habermas. A análise discursiva resultou de 16 entrevistas realizadas com docentes de duas universidades, pública e privada. Ao relacionar na análise o funcionamento das marcas intradiscursivas em relação ao interdiscurso evidenciaram-se os efeitos de sentidos: o esvaziamento ético-moral social como transcendente à universidade; o resgate da ética humanística na formação dos discentes da saúde; o docente como referência para a formação éticomoral dos discentes; as determinações do sistema como justificação moral; e a ética dialógica para o enfrentamento dos dilemas morais. Evidenciou-se que a memória discursiva do objeto ética no ensino na área da saúde está em processo de consolidação.

DESCRITORES: Ética. Discurso. Enfermagem. Medicina. Filosofia.

\section{ETHICAL AND MORAL ISSUES IN EDUCATING NURSES AND PHYSICIANS: EFFECTS OF MEANINGS IN FACULTY DISCOURSES}

\begin{abstract}
This paper aimed at understanding the effects of meaning in the discourses of medical and nursing school professors concerning ethical-moral issues in formal education. This is a qualitative study based on the Discourse Analysis theory, the French line of Pêcheux, in dialogue with Habermas' theory. Discursive analysis resulted from 16 interviews with two public and private Universities' professors. Upon relating professors' discourse analysis, the mechanics of intra-discursive marks to the interdiscourse, following meaning effects were noted: the social ethical-moral emptying as transcending the university; recovering humanistic ethics when graduating students in the health field; the faculty member as a reference to the ethical-moral formation of the students; the systems' determinations as moral justification; and dialogical ethics when facing moral dilemmas. This study evidenced that discursive memory of the ethics object in teaching in the health area is still in consolidation.
\end{abstract}

DESCRIPTORS: Ethics. Discourse. Nursing. Medicine. Philosophy.

\section{LA CUESTIÓN ÉTICA Y MORAL EN LA FORMACIÓN DE LOS ENFERMEROS Y MÉDICOS: EFECTOS DE SIGNIFICADO EN LOS DISCURSOS DE LOS DOCENTES}

\begin{abstract}
RESUMEN: Esta investigación tuvo como objetivo comprender el significado de los efectos producidos en el discurso de los docentes de enfermería y de medicina sobre la cuestión ética y moral en la formación de los estudiantes. Es una investigación cualitativa basada en la teoría del Análisis del Discurso, de la línea francesa de Pêcheux, en diálogo con la teoría de Habermas. Los resultados del análisis discursivo se obtuvieron de 16 entrevistas con los profesores de dos universidades, pública y privada. Al vincular el análisis del discurso de los docentes al funcionamiento de las marcas intradiscursivas en relación al interdiscurso, se mostraron los efectos de sentido: el vacío ético, moral y social como trascendente a la universidad; el rescate de la ética humanista en la formación de los estudiantes del área de la salud; el profesor como una referencia en la formación ética y moral de los estudiantes; las determinaciones del sistema como justificación moral; y el diálogo ético para enfrentar los dilemas morales. Se hizo evidente que en la memoria discursiva de la educación en salud el objeto de la ética se encuentra en proceso de consolidación.
\end{abstract}

DESCRIPTORES: Ética. Discurso. Enfermería. Medicina. Filosofia. 


\section{INTRODUÇÃO}

A educação e a saúde são duas áreas intimamente imbricadas que podem ser utilizadas como aferidoras do nível de desenvolvimento de uma nação. Em nosso país, infelizmente, embora ressaltadas como importantes em todos os discursos políticos, estes fundamentais pilares da construção de um desenvolvimento sustentável enfrentam sérias dificuldades, com reflexos diretos no cotidiano da população.

Na saúde, as queixas não se restringem à carência de recursos e investimentos, mas também à ausência de humanização no atendimento, bem como à perda do senso ético-moral e da responsabilidade de alguns profissionais desta área, manifestadas por ações de desconsideração com as pessoas, de negligência, imprudência e até mesmo imperícia, evidenciando uma decadência no sistema de saúde. Chegou-se ao estágio de reconhecimento público da falta de humanização na assistência prestada ao usuário do Sistema Único de Saúde (SUS) quando o Ministério da Saúde publicou, em 19 de junho de 2001, a Portaria No 881 criando o Programa Nacional de Humanização da Assistência Hospitalar (PNHAH) ${ }^{1}$ onde na introdução ressalta que a formação dos profissionais da saúde direcionada exclusivamente ao desenvolvimento do conhecimento técnico-científico teve como reflexo na sociedade a perda de princípios ético-morais, os quais deveriam ser a sustentação da assistência pautada pelo respeito à vida. ${ }^{1}$

Dilemas éticos e morais permeiam o cotidiano do trabalho dos profissionais da saúde. Frequentemente, orientando seus discentes, tanto na sala de aula como em campo de estágio, os docentes se deparam com situações que requerem um posicionamento definido. A postura assumida servirá como referência positiva ou negativa ao seu discente. A ética e a consciência moral não devem ser exclusivamente trabalhadas nas disciplinas que estudam e abordam estas temáticas, mas devem permear a prática dos docentes, perpassando todas as disciplinas.

Investigando os estressores comuns e diferenciados entre a equipe multiprofissional que trabalha na sala de cirurgia, o relacionamento interpessoal emergiu como estressor mais frequente e significativo para toda equipe, sendo o paciente o menor gerador de estresse. ${ }^{2}$ Os médicos e enfermeiras se sentiam habilitados tecnicamente para atender o paciente, mas diziam que não foram preparados para outros princípios envolvidos direta ou indiretamente no relacionamento interpes- soal. O relacionamento interpessoal gera estresse desencadeado por fatores éticos e morais, como conflitos diversos, discussões, disputa de poder, despreparo de alguns profissionais que fazem parte da equipe, desrespeito tanto com o paciente quanto entre a equipe, brincadeiras inoportunas, situações forçadas, descaso, falta de comprometimento e cooperação de alguns profissionais e falta de reconhecimento e reciprocidade. ${ }^{2}$

Outra pesquisa, investigando conflitos e dilemas éticos vivenciados por enfermeiros de Centro Cirúrgico, identificou vivências de conflitos resultantes aos "maus tratos, desrespeito e violência entre profissionais onde os pacientes não conseguem ser sujeitos da ação". 3:112 Os conflitos e dilemas vivenciados impõem escolhas difíceis, gerando angústias, sendo as ações muitas vezes fundamentadas não pela moral e ética, mas sim pelo domínio técnico. ${ }^{3}$

O verdadeiro educador deverá contemplar quatro dimensões: técnica, política, estética e ética. ${ }^{4}$ Frente a estas competências que o docente deve ter, emergem algumas questões que incitam a reflexão: como saber se um docente universitário da área da saúde está apto a desenvolvê-las na sua prática diária do ensino? Será que ele foi preparado para ser educador ou apenas tem competência técnica? A discussão sobre conflitos ético-morais permeia todas as disciplinas de formação dos profissionais da saúde ou é restrita à disciplina específica?

A escolha deste tema para realização da pesquisa emergiu da experiência como enfermeira e professora universitária, ao perceber muitos docentes preocupados com o conhecimento técnico-científico, deixando em segundo plano ou desconsiderando, com seu exemplo, a importância e o estímulo à consciência moral no aluno. A certeza da relevância do tema foi concretizada ao evidenciar poucos pesquisadores dedicados ao estudo da ética na formação dos profissionais da área da saúde. ${ }^{5}$ Uma pesquisa bibliográfica relacionando ética e educação identificou aumento no número de publicações sobre este tema; contudo, constatou pequeno quantitativo, sendo a maioria textos especulativos e críticos, inspirados em referenciais teóricos da filosofia, sociologia e psicologia moral e pouca pesquisa empírica. ${ }^{6}$ Resultados parecidos foram encontrados nos artigos publicados na Revista Brasileira de Enfermagem, apontando aumento gradativo nas publicações sobre ética e bioética. ${ }^{7}$ Neste cenário fértil definiu-se o problema de pesquisa que norteou a investigação: que efeitos de sentidos, no discurso docente em enfermagem e 
medicina, apontam a problematização ético-moral na formação do discente?

Muitos problemas de pesquisa invadem outras áreas, havendo, muitas vezes, necessidade de romper fronteiras, agregando e aglutinando diferentes disciplinas; ${ }^{8}$ essa desterritorialização do saber ocorreu nesta pesquisa, pois houve necessidade da interlocução com diversas áreas do conhecimento, tais como filosofia, sociologia e educação, para compreender a problemática emergente da área da saúde. Esta interdisciplinaridade foi abordada por Habermas, ${ }^{9}$ quando afirmou que a filosofia faz um elo com as outras ciências, colaborando para esclarecer os fenômenos estudados por meio de procedimentos e argumentações indicadores de racionalidade; enquanto a filosofia tiver que "contribuir para o aclaramento das intuições quotidianas adquiridas no curso da socialização, ela terá que partir, pelo menos virtualmente, da atitude dos participantes da prática comunicativa quotidiana". 9:67

A filosofia como pano de fundo foi utilizada para alcançar o objetivo traçado: compreender os efeitos de sentidos produzidos no discurso dos sujeitos docentes de enfermagem e medicina sobre a questão ético-moral na formação dos discentes, tendo em vista contribuir à reflexão sobre a formação dos profissionais da saúde.

Considerando-se as questões éticas parte do pensamento filosófico, ${ }^{10}$ optou-se em abordar o problema levantado através da linha filosófica, direcionando a questão de estudo à fundamentação teórica de dois filósofos, Habermas e Pêcheux, estabelecendo uma conexão entre os saberes manifestos no discurso dos docentes.

\section{METODOLOGIA}

Esta pesquisa qualitativa aponta para a direção metodológica da teoria da Análise de Discurso (AD), da linha francesa de Michel Pêcheux, estabelecendo uma interlocução teórico-metodológica com a Teoria da Ação Comunicativa e Ética do Discurso de Habermas.

A AD é considerada uma "disciplina de interpretação" 11 e uma disciplina de "entremeio", ${ }^{12}$ isto porque trabalha "o entremeio, fazendo uma ligação, mostrando que não há separação estanque entre a linguagem e sua exterioridade constitutiva". ${ }^{12: 25-6}$

A escolha da AD se justifica por permitir trabalhar os sentidos do discurso produzidos pela ideologia, história e linguagem do sujeito, e não com o conteúdo do texto, conforme a Análise de Conteúdo. ${ }^{13}$
$\mathrm{Na} \mathrm{AD}$, geralmente o corpus define o objeto de pesquisa, pois ele não preexiste. $\mathrm{O}$ material já existente, como documentos, é considerado por Pêcheux como corpus de arquivo e o empírico é aquele construído especialmente para a pesquisa ${ }^{14}$ seguindo critérios teóricos, ${ }^{15}$ como ocorreu neste estudo, com o material linguístico produzido pelas práticas discursivas resultantes de 16 entrevistas com docentes universitários dos cursos de graduação em enfermagem e medicina. A seleção dos sujeitos-docentes ocorreu em um processo cíclico, seguindo os seguintes critérios: diretores e vice-diretores dos cursos de graduação pesquisados; docentes dos cursos de enfermagem e medicina, com seleção por conveniência do tipo bola de neve; ${ }^{16}$ com mais de nove anos de atuação na vida acadêmica; titulação mínima de especialista; e aceitação em participar da pesquisa. Os docentes foram separados em quatro grupos; dois grupos formados por docentes da universidade pública (um com quatro da enfermagem e outro com quatro da medicina) e outros dois grupos da universidade privada, na mesma composição. A saturação dos dados e a quantidade de material linguístico coletado determinaram o encerramento das entrevistas.

O cenário da investigação envolveu duas universidades, ambas com Faculdades de Enfermagem e Medicina, localizadas na região da Grande Porto Alegre-RS; o motivo da escolha de uma universidade pública e outra privada para realizar o estudo foi a possibilidade de evidenciar a heterogeneidade do discurso dos docentes que trabalham em instituições com filosofias e normas diferentes, garantindo a representatividade.

Para construção do corpus utilizou-se uma ficha informativa, com dados de identificação e informações profissionais, a qual serviu para traçar o perfil dos participantes da pesquisa, e roteiro de entrevista semi-estruturada, com 13 perguntas divididas em três grandes tópicos, os quais direcionaram a entrevista: 1) questão da ética na educação superior; 2) conflitos morais na educação superior; e 3) sobre o PNHAH. ${ }^{1}$

A pesquisa foi conduzida de acordo com os padrões éticos exigidos pela Resolução No $196 / 96,{ }^{17}$ com assinatura do Termo de Consentimento Livre e Esclarecido pelo sujeito-professor. O Comitê de Ética e Pesquisa da Universidade Federal do Rio Grande do Sul aprovou a pesquisa, emitindo protocolo $\mathrm{N}^{\circ}$ 2007787, em dezembro de 2007.

Foi realizado um estudo piloto com o objetivo de avaliar as questões formuladas na entrevista, 
bem como fazer um ensaio de análise de discurso. As entrevistas foram agendadas por contato telefônico, pessoalmente ou por e-mail, no local e hora de melhor conveniência aos docentes, ocorrendo individualmente, primeiramente com os diretoresprofessores dos cursos de graduação estudados e posteriormente com demais professores.

O percurso analítico realizado nesta pesquisa foi: estabelecimento do corpus discursivo conforme objetivos da pesquisa; realização das entrevistas e transcrição do material linguageiro; conferência das transcrições para validação; realização de leituras e releituras do material linguístico; identificação dos eixos temáticos a partir dos objetivos da pesquisa; definição das marcas linguísticas, partindo do estranhamento e da constatação do aparecimento repetitivo das mesmas nas formulações discursivas; realização dos Recortes Discursivos (RDs) para a análise, guiados pelas marcas linguísticas e posições discursivas identificadas; associação dos mesmos com as condições de produção e relação com o acontecimento; articulação dos RDs às redes de significações; evidenciação dos efeitos de sentidos que caracterizaram a posição do sujeito-docente; e reflexão dos efeitos de sentidos à luz do referencial teórico com interface entre Pêcheux e Habermas. Durante toda trajetória da análise realizou-se o movimento de vai e vem entre o intradiscurso e o interdiscurso, tomando as marcas linguístico-discursivas como pistas, para descrever o funcionamento do discurso e buscar os sentidos possíveis.

Identificou-se o Sujeito-docente pela sigla $\mathrm{SD}$, seguido da letra E ou M representando o curso ao qual pertence, Enfermagem (E) ou Medicina $(\mathrm{M})$, e o número correspondente à ordem sequencial da realização das 16 entrevistas.

\section{APRESENTAÇÃO E DISCUSSÃO DOS DADOS}

Frente ao objeto simbólico pesquisado, tentou-se significar os efeitos de sentidos conforme sua relação com as condições de produção do discurso, encontrando um ponto comum que permitisse fazer a interface entre os filósofos estudados. No percurso da análise, o estranhamento e o modo repetido pelo qual apareciam as marcas intradiscursivas não, tem que e ética nos discursos dos sujeitos-docentes determinaram a escolha para que estas guiassem os recortes analisados; complementou-se a análise com as marcas todo(a)(s), eu, nós, ele(s), você e a gente, permitindo ampliar as relações e configurar a posição do sujeito.
Com relação à marca discursiva ética evidenciou-se, muitas vezes, seu funcionamento como adjetivo, tais como: formação, princípios, postura, questão, valores, comportamento, prática, aparato, ciência, padrões, compromisso, visão, preceitos, tradição, construção, disciplina, crise, dilemas e conflitos. Desta forma o seu sentido, pela função adjetiva que assume, fica diluida entre todas essas outras esferas que apontam ao mundo da vida, surtindo o efeito de sentido de que a ética está em tudo.

Nas formulações discursivas onde ética apareceu como substantivo foram produzidos sentidos contraditórios, como: valorização, a ética é fundamental (SDE8), versus desvalorização, não existe na cultura da sociedade a valorização adequada da ética (SDM10); interesse, tentar passar algumas coisas também de moral e ética, de como atender o paciente, como se comportar, então algumas coisas a gente passa na prática (SDM16) versus desinteresse, a questão ética pra eles é muito pequena. [...] se espera muito pouco no sentido de ética né? Eu vejo o futuro muito ruim (SDM4); resgate, o grande retorno, tem que ser feito nesse sentido; de resgatar através da ética (SDM6), versus crise, não está sendo dada a importância à ética de um modo geral (SDE2); presença da ética no ensino, o ensino da ética permeia todos os dias e todos os anos, quer dizer, é no dia-a-dia que o aluno vê com o procedimento do professor (SDM11), versus pouca ética no ensino, apesar da ética e a moral né, serem tópicos que deveriam perpassar toda a formação do acadêmico de qualquer área, na minha percepção ela ainda é pouco, hã, aprofundada (SDE3); e esforço, nós temos que mostrar pro aluno que ele tem que seguir um norte, né? Que norte é esse? É o norte da ética, né? (SDE7), versus indignação, onde está a ética desse negócio, do médico que não pede o exame tal que tem que pedir, porque o sistema não paga? (SDM9).

Em alguns recortes discursivos percebeu-se o deslocamento entre ética, educação e humanização, criando uma associação genérica, vinculando a ética com a educação e a humanização. Também constatou-se a não diferenciação entre ética e moral, aparecendo como sinônimos.

A marca linguística não foi muito encontrada, gerando estranhamento por representar uma posição de negação frente ao tema estudado e produzindo uma multiplicidade de recortes discursivos e de efeitos de sentidos. Quanto ao seu funcionamento, encontraram-se no discurso significados de rejeição, ausência, alteridade, vazio, absurdo e impossibilidade; ${ }^{18}$ e ainda carência, falta, incapacidade e rechaço. 
O não produziu efeitos de sentidos de carência ética nos discentes, na família, na sociedade, na universidade, no sistema de saúde e nos profissionais da saúde. Nos discentes, produziu efeito de falta de valores éticos, falta de educação, falta de limites, falta de amadurecimento e rechaço do discente em relação ao paciente pobre, como enuncia o SDE14: já tive situações de o aluno ir na casa [do paciente] $e$ [ao] chegar no posto [me disse] [...]: "eu não sei porque que eu tenho que fazer isso, porque eu não sou obrigado a ver pobreza, eu não sou obrigado a sentir cheiro de pobre, [...] não sou obrigado a ver isso".

A marca não ligada aos docentes produziu efeito de sentido: de negação de certas atitudes e da supremacia do compromisso; incapacidade de resolver certas situações conflitantes geradoras de dilemas morais.

A marca não associada à ética reforçou os efeitos de sentidos de: responsabilidade da família na formação de valores nos filhos; imaturidade e suposta carência ética na maioria dos discentes que ingressam no ensino superior; e que a formação ética será alcançada ao se unir conhecimento técnico-científico e humanização. A marca discursiva moral, ao se unir ao não, produziu efeito de apagamento da memória dos dilemas morais vivenciados pelos docentes.

$\mathrm{Na}$ análise do funcionamento da marca discursiva tem que, se considerou o posicionamento de Habermas em relação à razão prática; ele diz que o sujeito ao se questionar o que devo fazer frente a um problema que envolve valores ou fins, as indicações para a ação dizem o que se deve fazer ou o que se tem de fazer, podendo ser entendido com sentido de dever, apontando além do horizonte da racionalidade de fins. ${ }^{19} \mathrm{Na}$ perspectiva da $\mathrm{AD}$, o uso de tem que mostra a inserção do sujeito na formação discursiva do profissional da área, cuja memória se constitui de enunciados que se referem ao que ele tem que saber fazer, deve ou não deve fazer. Assim, conforme o movimento do jogo discursivo, a análise dos recortes guiados pela marca discursiva tem que apontam a diversos efeitos de sentidos de deveres do docente, do discente e da universidade, para desenvolver a questão ética e dos princípios morais; além disso, aparecem efeitos de necessidade de mudança, transformação e avanço; e necessidade de resgate da ética.

No discurso emergiu como o docente tem que ser para servir como exemplo ético-moral para seus discentes: ético e humano, dotado de conhecimento, paciência, disponível para a pro- ximidade do paciente e do discente, voltado a compreender o acadêmico e paciente, a preocuparse com a formação do futuro profissional, a dar oportunidades, a impor limites, a dar testemunho, a ser autêntico e único, a amadurecer, crescer e obedecer leis. O docente materializa no seu discurso como deve ser o discente, apontando efeitos de sentidos com a marca tem que, indicando que deve ser criativo, aprender, avaliar-se, responder pelas coisas que faz, aprender a perder, arcar com as consequências dos seus atos, fazer escolhas, pensar, enxergar, respeitar o outro, saber atender o paciente, ter conhecimentos específicos e habilidades, associar conhecimentos, entender a realidade, falar, calar quando necessário, preparar e apresentar trabalhos, trabalhar com o principio ético-moral, avançar, evoluir, tomar decisões, ser educado, desenvolver aspectos éticos, dar retorno ao docente e registrar as informações repassadas por este. Quanto à universidade, o discurso mostrou o efeito de sentido de que esta deve enfocar a questão ética junto aos conhecimentos técnicos, trabalhar reforçando e buscando princípios éticomorais, bem como escolher docentes que atendam estes princípios.

O efeito de sentido de mudança, transformação e avanço, direciona-se aos docentes, aos usuários do serviço de saúde, à necessidade de humanização e ética. O efeito de sentido de resgatar a ética emerge nos recortes: eu acho que tem muito que tem que ser feito ainda [...] infelizmente a prática e o exemplo do dia-a-dia mostra que alguma coisa tem que ser feita (SDE2); e talvez o grande caminho, o grande retorno, tem que ser feito nesse sentido; de resgatar através da ética [...] tem que ser por aí (SDM6).

Ainda outros efeitos foram identificados com a marca discursiva tem que, como: ausência dos pais na formação ética do jovem por necessidade de estar trabalhando, porque tem que pagar as contas, tem que fazer isso, fazer aquilo? (SDM4); desinteresse do governo pelo funcionamento do sistema de saúde ao dizer: isso é uma rede, é uma rede organizada, e que tem que funcionar, e onde não funciona mais, porque não há um interesse em nossos governantes que isso funcione mais (SDE7); sistema de saúde mecanicista, ao dizer: tem que tomar banho em tal horário é essa, esse mecanicismo, [...], continuam achando que o corpo é uma máquina que tem que ter horário [...] tem que resolver naquele momento (SDE12); e conflito do professor frente a um dilema com o aluno, ao enunciar: nós tivemos que chamá-lo. Furto, a gente sabia que era e tal e chamamos e ele negou. Dai, nós tivemos que apresentar provas, [...] a gente teve que 
apresentar provas e tal. [...] teria que encaminhá-lo para a Polícia Federal. [...] isso é complicado! (SDM11).

As outras marcas discursivas definidas produziram efeitos diversos conforme o movimento discursivo. Evidenciou-se a alternância do uso dos pronomes eu, nós, ele(s), você, nós conforme o contexto: o pronome na terceira pessoa eles significava discentes ou pacientes; ele se referia ao discente ou ao curso de graduação no qual atuava; o pronome você, indicou uma referência genérica com indeterminação, podendo referir-se ao discente, mas também à interlocutora e inclusive ao enunciador que fazia a exemplificação. $\mathrm{O}$ pronome indefinido todo(s) reforçou o sentido de totalidade do conjunto de sujeitos aos quais se remetia, produzindo sentido de generalização; e o sintagma nominal a gente assinalou seu pertencimento ao grupo de docentes, produzindo o efeito do conjunto.

O processo argumentativo dos sujeitos-docentes sobre justificação moral relativa à formação ética do discente da enfermagem e medicina, o jogo discursivo, os recortes analisados com as marcas linguísticas ética, não e tem que, juntamente ao uso de pronomes, permitiram sugerir cinco efeitos de sentidos, fortemente marcados no discurso dos sujeitos- docentes, denominados: esvaziamento ético-moral social: transcende a universidade; resgate da ética humanística na formação dos discentes da saúde; o docente: referência para a formação ético-moral dos discentes; justificação moral: determinações pelo sistema; e a ética dialógica para o enfrentamento dos dilemas morais.

\section{Esvaziamento ético-moral social: transcende a universidade}

Os recortes com ética(o) evidenciaram efeitos de sentidos de crise ética vivenciada pela sociedade, omissão da família e da escola no processo de formação ético-moral e educação do jovem, chegando à universidade sem limites e carente de princípios ético-morais. Os sujeitos aderiram a um saber frequentemente circulante no discurso pedagógico, onde a família deveria ser a responsável pela formação moral e educação do sujeito, confundindo, por vezes, ética e educação. A análise dos recortes com a marca não, reforçou o sentido da falta de valores éticos e educação dos discentes, a universidade que pouco tem a fazer, e o deslocamento do tema ética para educação. A marca tem que foi reforçada pela marca não nos recortes, produzindo efeito de negação do dever cumprido.
No discurso emergiram posições opostas, tanto de valorização dos princípios ético-morais na formação do discente quanto falta de comprometimento com o tema da ética. Esta falta é atribuída ao outro, à crise ético-moral social, à família e à escola, transpondo a universidade. Dessa forma, nessa posição, os docentes não assumiriam a responsabilidade, nem problematizariam a questão da ética. No discurso emergiu a não institucionalização da formação ético-moral do discente pela universidade, passando a ser responsabilidade da família que repassa à universidade e, por sua vez, transfere aos docentes que, por meio de ação individual e intencional, tentam suprir esta deficiência na formação dos discentes. Como alguns docentes não se filiam discursivamente a esse sentido, o discurso reforça a necessidade de institucionalizar posturas que desenvolvam a consciência coletiva do corpo docente. Nos termos da AD, seria adequado dizer que há necessidade de criar memória específica sobre a ética, que não está de todo presente no discurso dos docentes, mas conforme apontam está em construção, o que é atestado pelos diferentes exemplos trazidos de suas experiências. Ao analisar este efeito de sentido, tentando fazer uma interligação entre Habermas e Pêcheux, se percebe que ambos creem nas três dimensões do mundo da vida (social, cultural e do sujeito) manifestandose no discurso, bem como valorizam a história na constituição do sujeito, tal como foi evidenciado: um sujeito- docentes marcado pela história e pelas modificações sociais, atravessado pela memória do dizer e do discurso outro.

\section{Resgate da ética humanística na formação dos discentes da saúde}

A marca ética(o) representa uma sistematização do discurso da saúde que circula nos meios acadêmicos atuais e foram adotados pelas Diretrizes Curriculares que determinam uma formação tradicional humanística, valorizando e preocupando-se com a formação ética dos discentes. ${ }^{20}$ Os recortes discursivos com a marca linguística não reforçaram os problemas existentes, apontados pelo PNHAH, de desumanização e distanciamento dos profissionais da saúde do paciente. $\mathrm{O}$ discurso mostra uma dicotomia em relação à portaria; contudo, há concordância que ela seja o reflexo de uma realidade existente no mundo da vida. A marca linguística tem que reafirmou o discurso humanístico e desejo de resgate, produzindo o significado de dever em várias posições: de rever a realidade vivenciada 
da formação do discente; de seguir as Diretrizes e o PNHAH; da universidade trabalhar a questão humana; e de formar enfermeiros e médicos conforme as competências gerais estabelecidas pelas Diretrizes. Na associação das marcas linguísticas ética e não emergiu o significado que a formação ética será alcançada unindo-se o conhecimento técnico-científico à humanização; e a associação entre ética e tem que evidenciou que algo tem que ser feito para mudar e transformar a teoria em prática. Percebem-se efeitos de: preocupação em relação à ética e de direcionamento ao seu resgate; contribuição da universidade para a formação ética do discente através do seu quadro docente; e necessidade de comprometer a universidade em trabalhar a questão humana. No discurso, o tecnicismo foi apontado como um dos motivos da desumanização na área da saúde; a sujeição ao aparelho técnico é reconhecida por Habermas, afirmando que a ciência e a técnica perpassam todas as instituições na contemporaneidade. Conforme Pêcheux, essa ocorrência que enfatiza a reprodução do mesmo sentido se deve ao efeito ideológico. Tanto Habermas quanto Pêcheux creem que o sujeito não determina sua forma de ser no mundo, mas é determinado por ele; embora o assujeitamento não seja total, e os sentidos "prontos" possam ser questionados ao significar, muitas vezes este se torna mero reprodutor desses sentidos, contribuindo para perpetuá-los.

\section{O docente: referência para a formação ético- moral dos discentes}

A marca discursiva ética(o) produziu o efeito de espelho, isto é, o modelo de referência ao qual a pessoa se identifica é determinante para sua postura ética; assim sendo, a criança se identifica com os pais e o discente com o docente. Por isso, o discurso enfatiza a importância do docente pensar e fazer de forma condizente, pois sua postura servirá de modelo ético-moral aos discentes. Mais uma vez, a marca linguística não reforçou o efeito evidenciado com a marca ética sobre a importância do modelo como referência para a formação ético-moral; o discurso aponta a dificuldade de viabilizar na prática a teoria. Nas formulações apresentadas com tem que aparece a participação ativa do docente na prática com o discente e o esforço dos sujeitos-docentes em aplicar na prática a teoria, destacando os deveres de ambos.

Os recortes com associações das marcas discursivas reforçaram a significação produzida anteriormente e a importância da vivência prática entre docente-discente, permitindo que ambos fiquem juntos frente aos mais diversos cenários, oportunizando ao docente desenvolver uma metodologia ativa com inserção de aspectos éticos como, por exemplo, no campo de estágio, onde o este pode mostrar uma postura ética modelo frente ao paciente e à equipe de trabalho, estimulando assim a formação ético-moral, juntamente a formação técnica. Ao perceber, no discurso dos sujeitosdocentes, as vozes das Diretrizes Curriculares, produzindo o efeito de unicidade, relacionou-se o efeito de monologismo, ${ }^{18}$ ou seja, quando diversos discursos são afetados pela mesma formação discursiva, reproduzindo uma homogeneidade ilusória; Habermas e Pêcheux consideram a ilusão da homogeneidade do discurso e na interlocução entre os sujeitos, conforme constatado.

\section{Justificação moral: determinações pelo sis- tema}

A marca discursiva ética(o) apontou à junção dos problemas de relações humanas aos problemas éticos; não, marcou o poder do sistema econômico dominante, o poder político permeando todas as áreas do conhecimento, o crescente avanço tecnológico e o tecnicismo produzindo relações desumanizadas na saúde e crise ética; e tem que significou que é dever do sistema político a saúde e a educação. A associação das marcas ética(o) e não permitiu: entrelaçar os interesses econômicos e históricos, apontando o problema atual de proliferação desordenada das escolas de nível superior, em especial as escolas médicas; denunciar a complexa relação político-econômico-social existente nas políticas públicas no sistema de saúde brasileiro, gerando problemas éticos na educação e dilemas entre docentes e profissionais da saúde; e o discente, que ao se tornar profissional, passa a priorizar o sistema econômico, que rege toda a sociedade. A associação entre ética(o) e tem que indicou o sentido de como deveria ser o atendimento à saúde, aliando conhecimento técnico à humanização e à ética, desencadeando uma reflexão sobre a situação do sistema de saúde no contexto sócio-políticoeconômico brasileiro e, conseqüentemente, sobre o PNHAH. Habermas supõe que todas as esferas de ação social são controladas pelo dinheiro e por uma administração estatal regulada por relações de poder; ${ }^{21}$ de forma semelhante, Pêcheux acredita que não se deve "ignorar as determinações econômicas que condicionam 'em última instância' essa reprodução/transformação, no próprio interior da produção econômica". 22:143 


\section{A ética dialógica para o enfrentamento dos dilemas morais}

Os sujeitos-docentes, ao serem perguntados sobre os dilemas morais enfrentados com os discentes, apresentaram diversas reações, tais como: silêncio propriamente dito, ou, o não-dizer; o apagamento da palavra ética; e a palavra moral pouco enunciada no discurso. A marca não evidenciou o dilema, confrontando posições diferentes possíveis; no jogo entre o dito e o silenciado produziu efeitos de incerteza do docente frente à tomada de decisão; não-julgamento das pessoas pelas suas condutas; incapacidade de resolver sozinho certas situações conflitantes geradoras de dilemas morais; rechaço do discente em atender pacientes pobres e sem condições; e oportunizar chance de recuperação aos discentes com desvio de conduta através do diálogo e tentativa de conscientização. A marca tem que produziu o efeito de como deve ser o educador e o efeito de dúvida dos docentes sobre a transformação do discente. A única associação possível foi entre as marcas discursivas moral e não, produzindo efeito de reflexão sobre os dilemas morais vivenciados. Em todas as situações de dilemas, o enfrentamento ocorreu por meio do diálogo entre docente e discente, com indicação da conduta ética a ser seguida, como forma de enfrentamento para resolução dos mesmos; logo, a interface entre Habermas e Pêcheux apontou ao uso da linguagem entre os sujeitos, visando à significação da realidade. As posições de docente e discente são distintas, mas compreendem a inserção no discurso da instituição social, que é a universidade. É nessa condição que se estabelece a interlocução. A prática discursiva adotada pelo docente, investido do papel educativo que lhe concerne na academia, incluiu sempre a prática da comunicação oral com o discente, antes da sanção. Cabe salientar a diversidade de dilemas, relacionados à área da saúde e ensino profissional universitário desta, emergidos no discurso, resultantes das vivências dos docentes com seus discentes, reforçando a importância do tema.

\section{CONSIDERAÇÕES FINAIS}

Existem várias formas de interpretar um discurso; a análise realizada foi apenas uma entre muitas outras, contudo permitiu compreender os efeitos de sentidos produzidos no discurso dos sujeitos docentes de enfermagem e medicina sobre a questão ético-moral na formação dos discentes. Os efeitos identificados apontam como heterogênea a posição do sujeito-docente universitário da área no enfoque da questão ético-moral. Destacam-se os sentidos: da área da saúde constituída pelo valor humanista, em conformidade com a legislação brasileira vigente; formação profissional universitária na área fortemente marcado pelo domínio dos conhecimentos e práticas, mesmo sob a desestabilização provocada pelas contradições presentes na realidade; a valorização das atividades práticas, onde a postura profissional ética do docente, frente ao paciente, passa a ser referência para a formação ético-moral do discente.

Nos pronunciamentos sobre os dilemas enfrentados nas suas práticas pedagógicas na área, considera-se, a partir da AD, que os docentes buscaram formular a sua interpretação, construir a sua posição sobre a questão ético-moral no ensino universitário; e apontam também, por meio de seus relatos, que a memória discursiva do objeto ética está ainda em processo de consolidação.

$\mathrm{Na}$ interface entre as perspectivas habermasiana e discursiva estudadas, ponderou-se, a partir das análises dos dilemas apresentados, a dificuldade de consenso, à medida que docentes e discentes representam posições diferentes no discurso pedagógico, as quais apareceram bem marcadas; porém, guiados por valores das áreas da saúde e da educação que extrapolam essa condição, abriu-se, para os sujeitos, a possibilidade de produção de sentidos compartilhados em outro lugar de enunciação.

Espera-se com esta pesquisa contribuir para a reflexão sobre a formação dos profissionais da saúde e estimular outros pesquisadores de enfermagem a filiar-se à linha da AD de Pêcheux.

\section{REFERÊNCIAS}

1. Ministério da Saúde (BR), Sistema Único de Saúde. Portaria No 881 de 19 de junho de 2001: Programa Nacional de Humanização da Assistência Hospitalar - PNHAH. Brasília (DF): MS; 2001 [acesso 2008 Jan 07]. Disponível em: sna.saude.gov.br/legisla/ legisla/informes/GM_P881_01informes.doc

2. Caregnato RAC. Estresse da equipe multiprofissional na sala de cirurgia: um estudo de caso [dissertação]. Porto Alegre (RS): Universidade Federal do Rio Grande do Sul. Programa de Pós-Graduação em Enfermagem; 2002.

3. Duarte LEMN. A ação estratégica dos enfermeiros frente a conflitos e dilemas éticos vivenciados em Centro Cirúrgico [dissertação]. Porto Alegre (RS): Universidade Federal do Rio Grande doSul. Programa de Pós-Graduação em Enfermagem; 2004. 
4. Perrenoud P. 10 Novas competências para ensinar. Porto Alegre (RS): Artes Médicas; 2000.

5. Rego S. A formação ética dos médicos: saindo da adolescência com a vida (dos outros) nas mãos. Rio de Janeiro (RJ): Fiocruz; 2003.

6. La Taille Y, Souza LS, Vizioli L. Ética e Educação: uma revisão da literatura educacional de 1990 a 2003. Educ Pesqui [online]. 2004 Jan-Abr [acesso 2008 Jun 26];30(1):91-108. Disponível em: http:/ / www.scielo. br/pdf/ep/v30n1/a06v30n1.pdf

7. Santiago MMA, Palácios M. Temas éticos e bioéticos que inquietaram a Enfermagem: publicações da REBEn de 1970-2000. Rev Bras Enferm [online]. 2006 Mai-Jun [acesso 2007 Mai 7]; 59(3):349-53. Disponível em:http://www.scielo.br/scielo.php?script=sci_artte $x t \& p i d=S 003471672006000300018 \& \operatorname{lng}=p \& n r m=i s o$

8. Morin E. A cabeça bem-feita: repensar a reforma, reformar o pensamento. $8^{\mathrm{a}}$ ed. Rio de Janeiro (RJ): Bertrand Brasil; 2003.

9. Habermas J. Consciência moral e agir comunicativo. Rio de Janeiro (RJ): Tempo Brasileiro; 2003.

10. Vázquez AS. Ética. $26^{\mathrm{a}}$ ed. Rio de Janeiro (RJ): Civilização Brasileira; 2005.

11. Pêcheux M. O discurso: estrutura ou acontecimento. $3^{\mathrm{a}}$ ed. Campinas (SP): Pontes; 2002.

12. Orlandi EP. Interpretação: autoria, leitura e efeitos do trabalho simbólico. $4^{\text {a }}$ ed. Campinas (SP): Pontes; 2004.

13. Caregnato RCA, Mutti R. Pesquisa Qualitativa: Análise deDiscurso versus Análise de Conteúdo. Texto Contexto Enferm. 2006 Out-Dez; 15(4):679-84.

14. Charaudeau P, Maingueneau D. Dicionário de Análise de Discurso. São Paulo (SP): Contexto; 2004.
15. Orlandi EP. Análise de Discurso: princípios e procedimentos. $6^{\mathrm{a}}$ ed. Campinas (SP): Pontes; 2005.

16. Polit DF, Beck CT, Hungler BP. Fundamentos de Pesquisa em Enfermagem: métodos, avaliação e utilização. $5^{\mathrm{a}}$ ed. Porto Alegre (RS): Artmed; 2004.

17. Ministério da Saúde (BR), Comissão Nacional de Ética em Pesquisa. Resolução No 196 de 10 de outubro de 1996: dispõe sobre as diretrizes e normas regulamentadoras de pesquisas envolvendo seres humanos. Brasília (DF): MS; 1996 [acesso 2008 Jan 08]. Disponível em: http:/ / www.bioetica.ufrgs.br/ res19696.htm\#cinf/textos.htm\#consentimento

18. Indursky F. A fala dos quartéis e as outras vozes. Campinas (SP): UNICAMP; 1997.

19. Habermas J. Para o uso pragmático, ético e moral da razão prática. In: Stein E, Boni LA, organizadores. Dialética e Liberdade: Festschrift em homenagem a Carlos Roberto Cirne Lima. Petrópolis (RJ): Vozes: Porto Alegre: UFRGS, 1993. p.288-304.

20. Ministério da Educação (BR), Conselho Nacional de Educação. Parecer $N^{\circ} 1.133 / 2001$ de 7 de agosto de 2001: diretrizes curriculares nacionais dos cursos de graduação em enfermagem, medicina e nutrição [pagina da internet]. Brasília (DF): Câmera de Educação Superior; 2001 [acesso 2008 Jul 2]. Disponível em: http://portal.mec.br/cne/ arquivos/pdf/CES1133.pdf

21. Habermas J. Diagnósticos do Tempo. Rio de Janeiro (RJ): Tempo Brasileiro; 2005.

22. Pêcheux M. Semântica e Discurso: uma crítica à afirmação do óbvio. $3^{\text {a }}$ ed. Campinas (SP): UNICAMP; 1997. 